\title{
Age-Related Grade Inflation Expectancies in a University Environment
}

\author{
Donald A. Loffredo and Rick Harrington \\ Department of Social \& Behavioral Sciences, School of Arts \& Sciences, University of Houston-Victoria, 3007 N. Ben Wilson, \\ Victoria, TX 77901, USA \\ Correspondence should be addressed to Donald A. Loffredo, loffredod@uhv.edu
}

Received 7 March 2012; Revised 9 September 2012; Accepted 16 September 2012

Academic Editor: Wayne Martino

Copyright ( 2012 D. A. Loffredo and R. Harrington. This is an open access article distributed under the Creative Commons Attribution License, which permits unrestricted use, distribution, and reproduction in any medium, provided the original work is properly cited.

Grade inflation is a recognized problem in higher education in the United States. Age, gender, and ethnic differences in discrepancies between student reports of their expected grade in each course and their expectations for general university grading practices were explored in a survey of 166 (mostly female) participants at a small upper-division university. Results revealed that while a small minority of students agreed that grading systems in college should only include A or B grades, a large majority of students expected A or B grades. Thus, student discrepancies between their expectations for grading systems and their expected class grades were in line with expectations that they should receive inflated grades. Results also revealed statistically significant age differences in grade expectation with students older than the age of 55 expecting lower grades relative to their younger counterparts.

\section{Introduction and Review of the Relevant Literature}

Grade inflation, the process of instructors assigning higher grades than is warranted, has been a perennial concern in academia. Particularly in the 1990s, faculty and academic administrators have made their voices heard regarding the issue to such an extent that even students are now beginning to voice concerns [1]. Due to these concerns, even some employers are now skeptical and wary of making employment decisions based solely on university grade point averages $[2,3]$.

Grade inflation has been reported as an acknowledged problem in higher education in the United States since the late 1960s [4-7]. However, not all research has reported grade inflation or a tendency toward it. Kohn [8] reviewed transcripts from 3,000 institutions of higher education and concluded that grades actually declined between 1975 and 1995. The majority of grade inflation studies, though, continue to report its existence.
Landrum [9] conducted a study on student expectation of grades in which 278 students in five different courses were asked about their own academic performance in class using both grade categories (A, B, C, D, and F) and descriptive criteria for grades ( such as $\mathrm{A}=$ distinguished, $\mathrm{B}=$ superior, $\mathrm{C}=$ average, $\mathrm{D}=$ below average, and $\mathrm{F}=$ failure) taken directly from the official Boise State University catalog. Descriptive criteria for grades in the Landrum study are found in the options following this sample item stem: my work in this class is best described as (a) a distinguished work, (b) a superior work, (c) an average work, (d) a below average work, and (e) a failure. Note that in this sample survey item the actual letter grades (A, B, C, D, and F) are not included as options, and only the descriptive criteria for each grade (e.g., average work) as stated in the Boise State University are listed as options. Landrum found that $72 \%$ of the students reporting average work when grade criteria were the only options for the survey item expected a whole letter grade lower than what they expected when the options for the survey item were letter grades only (A-F). After converting letter grades and 
the descriptive criteria for each grade to grade point average (GPA) numbers $(\mathrm{A}=4.0, \mathrm{~B}=3.0, \mathrm{C}=2.0, \mathrm{D}=1.0$, and $\mathrm{F}=$ 0.0 ), Landrum found a statistically significant higher GPA for the average expected letter grade (3.03) than for the survey item that included only grade criteria $(\mathrm{GPA}=2.43)$.

One of the most interesting and perhaps unsettling explanations of grade inflation is student sense of entitlement, a right to high grades without earning them. Often, students have not been held to high academic standards in the past and believe they deserve high grades [10]. There appear to be no studies published to date on the possible specific relationship between secondary school grade inflation and university or college grade inflation. Twenge and Campbell assert that "students are increasingly inundated with selfinflating messages throughout grade school" and that "these students then enter college with a sense of entitlement to grades, which is reinforced by evidence of grade inflation in U.S. college and universities" [11] (page 3).

Ciani et al. [12] examined gender differences in academic entitlement among college students and defined academic entitlement as a sense of entitlement to an A grade, the right to argue about a grade, or the belief that one does not have to put in much effort to receive a high grade. In the first of two studies they found that males reported significantly more entitlement than females and that this relationship was constant among classes. In their second study, participants were assessed before and after a class. The researchers found similar results and concluded that academic entitlement is more likely due to a characteristic of the student rather than the classroom context.

Although one study by Ciani et al. [12] reported significant gender differences in academic entitlement among college students with males reporting more academic entitlement, no studies examining the relationship between age and expectancies related to grade inflation have been published; Landrum [9] reported a significant degree of expected grade inflation but did not examine age, gender, or ethnic differences. The Landrum study was apparently the only study in the research literature that specifically focused on expected grade inflation. Kuh and $\mathrm{Hu}$ [13] reported that white university students ( $88 \%$ of their sample) uniformly achieved higher grades than students of color but did not examine the relationship between ethnicity and grade expectations.

Since there has been reported a significant gender difference in academic entitlement [12] with males reporting more academic entitlement [9], the first hypothesis for this study was that there will be gender differences in expected grade inflation in college. The second hypothesis was that there will be age differences in expected grade inflation because each successive generation has shown increasing indicators of narcissism or a sense of entitlement [11]. The third hypothesis was that, because there are reported ethnicity differences in obligation and entitlement [14] and entitlement can lead to expectations of grade inflation, there might be ethnic differences in expectations of grade inflation. Last, just as in the Landrum [9] study, there might be a significant difference for participants between the average expected letter grade
TABLE 1: Student characteristics.

\begin{tabular}{lcc}
\hline Gender & Age & Ethnicity \\
\hline Male $=9 \%$ & $<25$ years $=26.5 \%$ & Caucasian $=58.4 \%$ \\
& $26-35$ years $=27.7 \%$ & African American $=14.5 \%$ \\
Female $=91 \%$ & $36-45$ years $=29.5 \%$ & Hispanic $=15.1 \%$ \\
& $46-55$ years $=13.9 \%$ & Asian American $=6 \%$ \\
& $56-65$ years $=2.4 \%$ & Other $=6 \%$ \\
\hline
\end{tabular}

converted to a GPA number and the average participant descriptive criteria for grades converted to a GPA number.

\section{Method}

2.1. Participants. Psychology, nursing, and education students were recruited from an upper level university to complete a survey regarding grade expectations and systems. A total of 166 (91\% female, 9\% male) completed the survey. Of these, $72.3 \%$ were undergraduates, and $27.7 \%$ were graduate students. Table 1 presents a breakdown of the demographic information of the sample.

2.2. Materials. Participants completed online an informed consent form, demographic information questions, and six survey grade inflation items presented in Table 2. Survey item (1) was "My work in this class is best described as" with six alternative answers. The six alternative answers were the description criteria of letter grades A, B, C, D, and F from the University of Houston-Victoria catalog with neither letter grades attached nor listed as alternative answers. A survey item similar to this was used by Landrum [9] in his 1999 study. This question was constructed to measure each participant's current assessment of work in the class surveyed without a typical letter grade. Survey item (3) was "What grade do you expect to receive in this course?" The six alternatives were typical letter grades. Survey item 2 was included to see if students believe grading systems in college should only include A or B grades because $72 \%$ of the students reporting average work in the Landrum [9] 1999 study expected a grade higher than a C. Survey item 2 was also included along with survey item 4 to make meaningful comparisons with survey items 1 and 3 .

2.3. Procedure. The participants were students enrolled in online classes during the 2007-2008 academic year. They completed the survey through a WebCT e-learning management system. All students completed the materials designed to assess their expectancies for class grades and university grading.

2.4. Research Design and Statistical Analyses. The study's design based on survey data was quasiexperimental. Pertinent descriptive statistics were used to organize, summarize, and simplify obtained data. A chi-square test for independence was performed to determine if there was a statistically significant relationship between grades based on description criteria for grades (survey item 1) and expected letter grades 
TABLE 2: Grade inflation survey questions.

(1) My work in this class is best described as
(a) excellent, superior achievement
(b) good, exceeding all requirements
(c) average, satisfactorily meeting all requirements
(d) poor, passing
(e) failing
(f) incomplete

(2) Grading systems in college should include only A or B grades.
(a) Strongly agree
(b) Agree
(c) Disagree
(d) Strongly disagree

(3) What grade do you expect in this course?
(a) A
(b) $\mathrm{B}$
(c) $\mathrm{C}$
(d) $\mathrm{D}$
(e) F
(f) Incomplete

(4) Which of the following best describes your general academic ability?
(a) I am an A student
(b) I am a B student
(c) I am a C student
(d) I am a D student
(e) I am an F student

(survey item 3). Since the data were number counts instead of averages, the above nonparametric statistical procedure was required. A repeated-measures $t$-test was performed to determine if there were statistically significant differences by age, gender, and ethnicity on the grade inflation measures (survey items in Table 2) between average grade based on criteria for the grade and average expected letter grade. A three-way independent-measures (IM) multivariate analysis of variance (MANOVA) was performed to determine if there were statistically significant differences by age, gender, and ethnicity on the grade inflation measures (survey items in Table 2). The Kruskal-Wallis test, a conservative nonparametric test, was used to examine age differences on the grade inflation measures. A chi-square test for independence was performed to determine if age distributions for undergraduate and graduate participants were similar to prevent any confounding between age categories and student status (undergraduate versus graduate).

\section{Results}

3.1. Descriptive Statistics. The descriptive statistical results for the grade expectancy variables were interesting.

Exactly $44.9 \%$ of the participants reported current grade point averages of 3.50 to $4.00,31.7 \%$ reported grade point averages of 3.00 to 3.49 , and $20 \%$ reported grade point averages of 2.50 to 2.99 . Only $3.3 \%$ of the participants reported grade point averages of 2.00 to 2.49 .

Just $13.9 \%$ of the participants described their current work in the class they were surveyed in (survey item 1) as excellent, superior achievement (A grade criteria). Another $60.8 \%$ of the participants described their current work in the class they were surveyed in (survey item 1) as good, exceeding all requirements (B grade criteria). Thus, $74.7 \%$ of the participants indicated that they met the criteria for an A or B grade in the class they were surveyed in. Only $21.7 \%$ of the participants described their current work as average, satisfactorily meeting all requirements (C grade criteria). The remaining $6 \%$ of the participants described their current work in the class they were surveyed in as poor, passing (D grade criteria). None of the participants described their work as failing or incomplete in the class they were surveyed in.

Only $15.1 \%$ of the participants strongly agreed $(6.6 \%)$ or agreed $(8.4 \%)$ that grading systems in college should include only A or B grades (survey item 2). However, $96.4 \%$ of the participants indicated that they expected to receive an $\mathrm{A}$ $(71.1 \%)$ or B $(25.3 \%)$ letter grade (survey item 3 ) in the course they were surveyed in, and $98.2 \%$ of the participants described their general academic ability (survey item 4 ) as an A student $(62 \%)$ or B student $(36.1 \%)$.

3.2. Inferential Statistics. A chi-square test for independence revealed a statistically significant difference between the grade based on description grade criteria (survey item 1) and expected letter grade (survey item 3 ), chi-square $(9, N=$ $166)=67.54, P<.001$. The average grade based on grade criteria (survey item 1) was 2.85 (standard deviation $=.69$ ) on a 4-point scale similar to GPA, while the average expected letter grade (survey item 3) was 3.67 (standard deviation $=.57)$. A repeated-measures $t$-test identified a statistically significant difference between grade based on grade criteria (survey item 1) and expected letter grade (survey item 3), $t(165)=-15.7, P<.001$.

A three-way independent-measures (IM) multivariate analysis of variance (MANOVA) was performed to determine if there were statistically significant differences by age, gender, and ethnicity on the grade inflation measures. The MANOVA indicated that there were no statistically significant differences by age, gender, or ethnicity although age differences on the grade inflation measures approached statistical significance, $F(24,444)=1.53, P=.052$. The observed power for age and ethnicity exceeded .80 . The observed power for gender was low (.40) and may have contributed to the lack of a statistically significant difference by gender on the grade inflation measures. The MANOVA did indicate that there was only one statistically significant interaction which was an age by ethnicity interaction, $F$ (78, $706)=1.33, P<.05$, partial eta squared $=.12$, on the academic ability measure, $F(13,706)=2.71, P<.01$, partial eta squared $=.21$. However, since there were three missing mean values in the cells, the significant interaction effect was suspect and not considered valid.

Because age differences in the above MANOVA on the grade inflation measures closely approached statistical significance $(P=.052)$, the Kruskal-Wallis test, a conservative 
nonparametric test, was used to examine only the age differences on the grade inflation measures. The Kruskal-Wallis test did indicate a statistically significant difference by age on the grade inflation measure of letter grade expectation, $H=9.97, P=.041$. Post hoc pairwise comparisons using the Mann-Whitney $U$ test indicated statistically significant differences between the 26-35 age group and the greater than 55 age group, $U=38, P=.011$, and between the 46-55 age group and the greater than 55 years age group, $U=19.5$, $P=.013$, on the grade expected in this course. The 26-35 age group expected higher grades (mean rank 26.02) than the greater than 55 age group (mean rank 19.5), and the 4655 age group expected higher grades (mean rank 15.15) than the greater than 55 age group (mean rank 7.38). A chi-square test for independence revealed no significant differences between the distribution of age groups for undergraduate versus graduate students in this study, chi-square $(4, N=$ 166) $=5.25, P=.26$, so age was not confounded with undergraduate/graduate status.

\section{Discussion}

Surprisingly, only $15.1 \%$ of the participants strongly agreed $(6.6 \%)$ or agreed $(8.4 \%)$ that grading systems in college should include only A or B letter grades (survey item 2). However, $96.4 \%$ of the participants indicated that they expected to receive an A $(71.1 \%)$ or B $(25.3 \%)$ letter grade (survey item 3 ) in the course they were surveyed in, and $98.2 \%$ of the participants described their general academic ability as an A student (62\%) or B student (36.1\%) (survey item 4). This position raises the interesting possibility that students want or expect grade variability (not only A and $B$ grades), but they assume it is other students and, not themselves, who are not A or B students. The high number of students expecting A or B letter grades (96.4\%) was somewhat surprising for this sample since only $76.7 \%(45 \%$ of the participants had grade point averages of 3.50 to 4.00 , while $31.7 \%$ had grade point averages of 3.00 to 3.49 ) reported current grade point averages of 3.00 or above.

As hypothesized, there was a statistically significant difference between participant responses to survey items (1) and (3). Survey item (1) answers had more participants choosing the description criteria for a B letter grade $(60.8 \%)$ than the description criteria for an A letter grade (13.9\%), while survey item (3) answers had more participants expecting an A letter grade (71.1\%) than a B letter grade $(25.3 \%)$. The use of familiar letter grades in survey question (3) led to higher (perhaps less objective) grade expectations.

Another interesting result was that although $74.7 \%$ of the participants indicated that they met the description criteria for an A or B grade (survey item 1) in the class they were surveyed in, $96.4 \%$ of the same participants indicated that they expected to receive an A or B letter grade (survey item 3 ) in the course. Thus, approximately $21.7 \%(96.4 \%-74.7 \%)$ of participants, even though they disclosed that they did not meet the criteria for an A or B grade in the course when they were surveyed, expected an A or B letter grade in the course. These results along with the statistically significant chi-square test for independence results and the repeated measures $t$-test results were similar to the results of Landrum's [9] 1999 study.

As hypothesized, there were significant age differences in expected grade inflation. The current study is the first of its kind to report statistically significant age differences in grade expectation. To our knowledge, no other study has been reported in the literature. The 26-35 age group in this study expected higher grades (mean rank 26.02) than the greater than 55 age group (mean rank 19.5), and the 46-55 age group in this study expected higher grades (mean rank 15.15) than the greater than 55 age group (mean rank 7.38). One possible explanation for these results is that the over 55 age group has more realistic grade expectations than either the 26-35 age group or the 46-55 age group. An alternative hypothesis for these results is that the younger age groups are more confident than the over 55 age group. A third possibility is that the younger students have a greater sense of entitlement.

As discussed in the literature review section, there is ample evidence that students have been increasingly experiencing a greater sense of entitlement since the 1990s that starts in secondary education or earlier, before students begin taking college classes [15-17]. They may have brought a sense of entitlement to the college classroom environment that in turn contributes to creeping grade inflation. Indeed, there appears to be a steady climb in indicators of a "culture of narcissism" in the United States that promotes exaggerated expectancies, an inflated sense of self, and entitlement [11]. Following the baby boomer generation, each successive generation has shown increasing indicators of narcissism [11]. Student entitlement has become so pervasive in higher education that Lippmann et al. [18] have reported strategies for dealing with students with a sense of entitlement.

The present study is limited since the comparison groups were unequal (only $2.4 \%$ of sample participants were over the age of 55) and the sample was not gender balanced. Therefore, the results may not generalize as well to males as females. Results of the MANOVA, however, found no gender differences. Though the power of the test was limited due to the small number of males in the sample, the lack of significance suggests that males do not differ in their expectancies. Since the observed statistical power for gender in the three-way MANOVA was low (.40) and likely contributed (only $9 \%$ of the sample participants were male) to the lack of a statistically significant difference by gender on the grade inflation measures, it was not surprising that there was no statistically significant differences found for gender in this study. This study should be repeated with a gender-balanced sample. The observed statistical power for ethnicity in the three-way MANOVA was more than adequate (.84) to detect a statistically significant difference, but no difference was found. Finally, to address any possible concern that age and status (undergraduate versus graduate) were confounded, a chi-square test for independence was performed and revealed no significant differences between the distributions of age groups for undergraduate versus graduate students. Thus, age was not confounded with status.

The present study is the first of its kind to report statistically significant age differences in grade expectations. 
Specifically, students older than the age of 55 expected lower grades than younger students. The current study also found that while a small minority of students agreed that grading systems in college should not include only A or B grades, a large majority of students expected A or B grades. Thus, student discrepancies between their expectations for grading systems and their expected class grades were in line with expectations that they should receive inflated grades.

\section{References}

[1] V. E. Johnson, Grade Inflation: A Crisis in College Education, Springer, New York, NY, USA, 2003.

[2] P. E. Barton and A. Lapointe, Learning By Degrees: Indicators of Performance in Higher Education, Educational Testing Service, Princeton, NJ, USA, 1995.

[3] N. Spinks and B. Wells, "Trends in the employment process: resumes and job application letters," Career Development International, vol. 4, pp. 40-45, 1999.

[4] A. Q. Barriga, Cooper, E. K. Gawelek M. A, K. Butela, and E. . Johnson, "Dialogue and exchange of information about grade inflation can counteract its effects," College Teaching, vol. 56, no. 4, pp. 201-209, 2008.

[5] J. Felton and P. T. Koper, "Nominal GPA and Real GPA: a simple adjustment that compensates for grade inflation," Assessment and Evaluation in Higher Education, vol. 30, no. 6, pp. 561-569, 2005.

[6] C. F. Eiszler, "College students' evaluations of teaching and grade inflation," Research in Higher Education, vol. 43, no. 4, pp. 483-501, 2002.

[7] J. Millman, S. P. Slovacek, E. Kulick, and K. J. Mitchell, "Does grade inflation affect the reliability of grades?" Research in Higher Education, vol. 19, no. 4, pp. 423-429, 1983.

[8] A. Kohn, "The dangerous myth of grade inflation," Chronicle of Higher Education, vol. 49, no. 11, p. B7, 1995.

[9] R. Landrum, "Student expectations of grade inflation," Journal of Research and Development in Education, vol. 32, no. 2, pp. 124-128, 1999.

[10] R. E. Redding, "Students' evaluations of teaching fuel grade inflation," American Psychologist, vol. 53, no. 11, pp. 12271228, 1998.

[11] J. M. Twenge and W. K. Campbell, The Narcissism Epidemic: Living in the Age of Entitlement, Free Press, New York, NY, USA, 2009.

[12] K. D. Ciani, J. J. Summers, and M. A. Easter, "Gender differences in academic entitlement among college students," Journal of Genetic Psychology, vol. 169, no. 4, pp. 332-344, 2008.

[13] G. D. Kuh and S. Hu, "Unraveling the complexity of the increase in college grades from the mid-1980s to the mid1990s," Educational Evaluation and Policy Analysis, vol. 21, no. 3, pp. 297-320, 1999.

[14] B. J. Brummel, "Investigating the role of obligation and entitlement in the prosocial disposition and citizen performance," Dissertation Abstracts International, vol. 69, no. 11-B, p. 7174, 2009.

[15] G. Cook, "Grade inflation reaches new heights," American School Board Journal, vol. 191, no. 6, p. 8, 2004.

[16] R. L. Ziomek and J. C. Svec, "High school grades and achievement: evidence of grade inflation," ACT Research Report Series 95-3, American College Testing Program, Iowa City, Iowa, USA, 1995.
[17] N. C. Weissberg, D. R. Owen, A. H. Jenkins, and E. Harburg, "The incremental variance problem: enhancing the predictability of academic success in an urban, commuter institution," Genetic, Social, and General Psychology Monographs, vol. 129, no. 2, pp. 153-180, 2003.

[18] S. Lippmann, R. E. Bulanda, and T. C. Wagenaar, "Student entitlement: issues and strategies for confronting entitlement in the classroom and beyond," College Teaching, vol. 57, no. 4, pp. 197-204, 2009. 


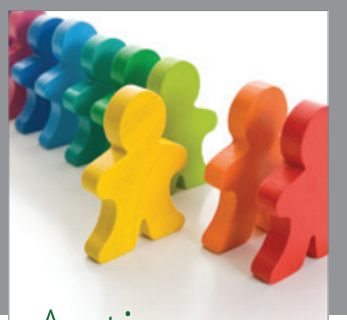

Autism

Research and Treatment
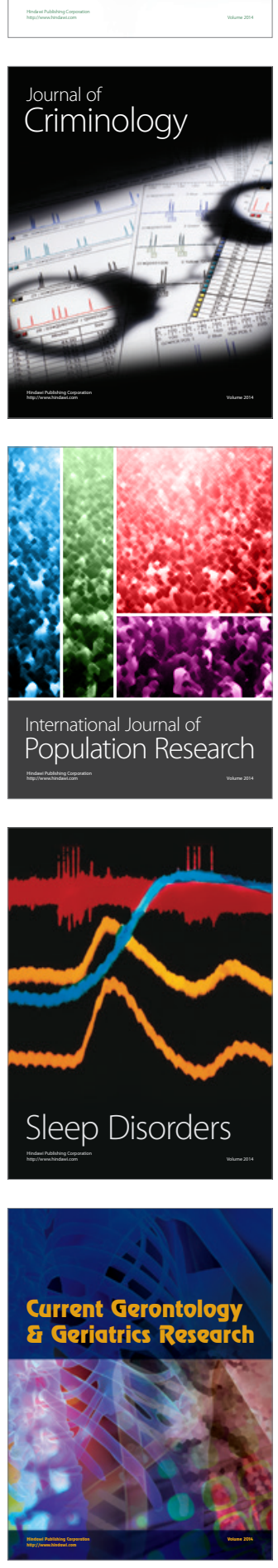
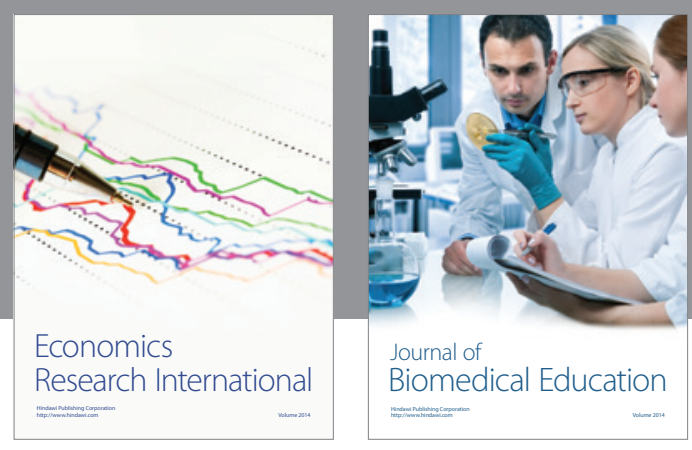

Journal of

Biomedical Education

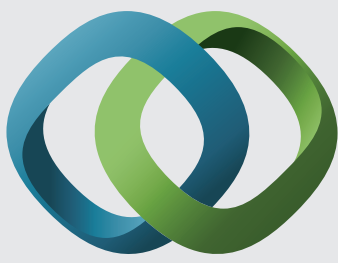

\section{Hindawi}

Submit your manuscripts at

http://www.hindawi.com
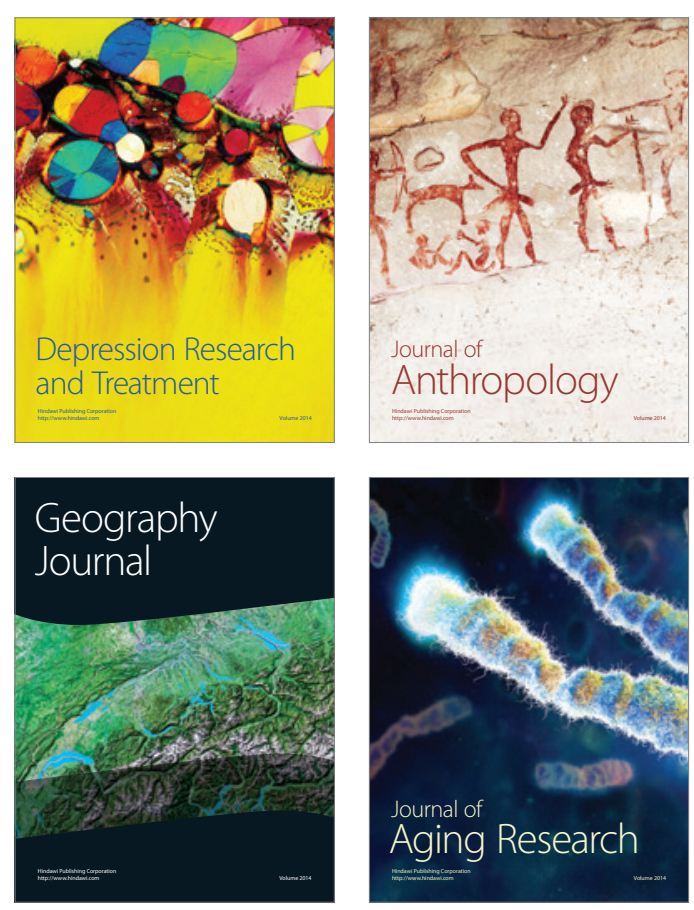

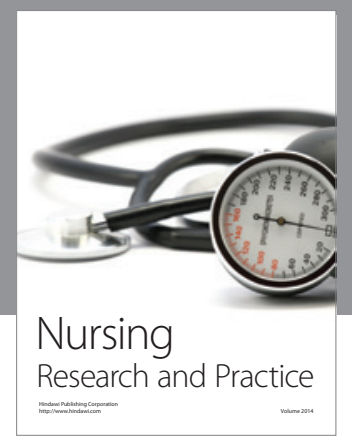

Nursing

Research and Practice

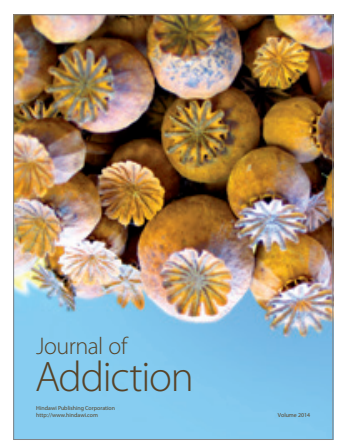

Child Development

Research

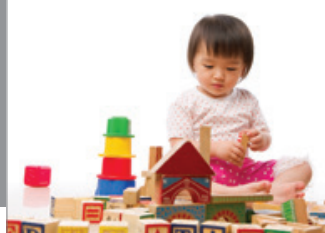

迥
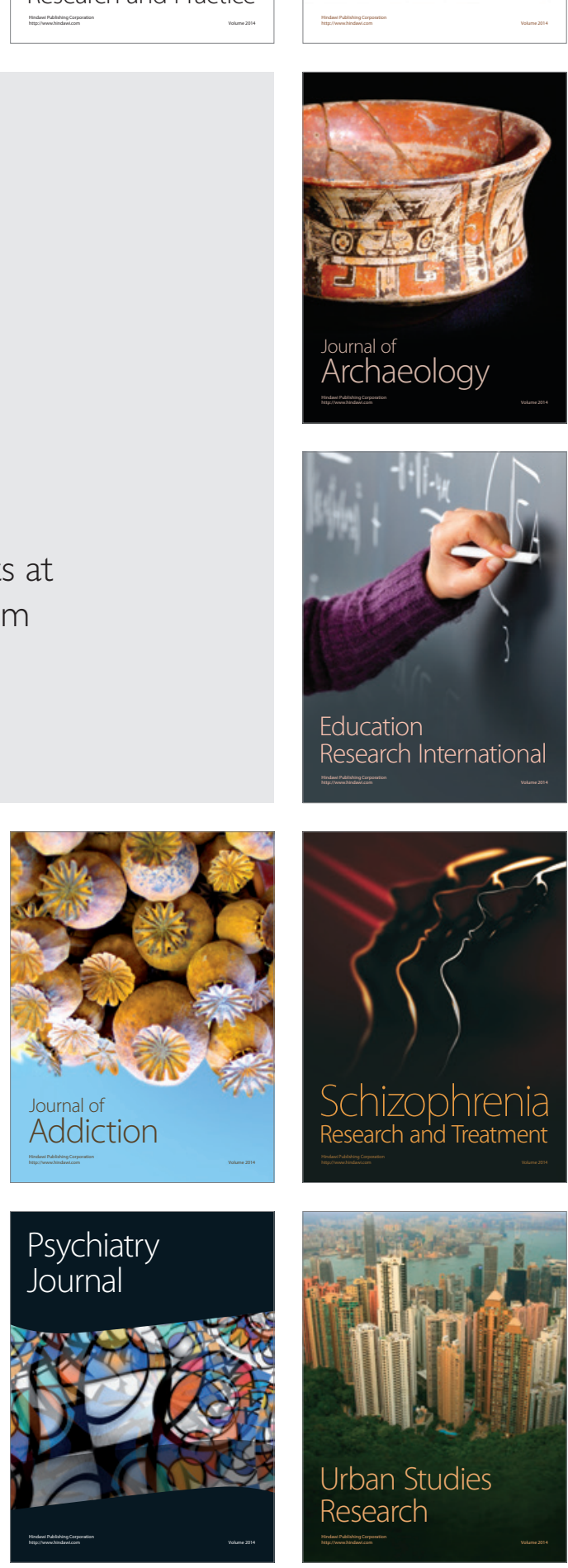